\title{
Impact of different light intermittence regimes on bacteria during simulated solar treatment of secondary effluent: Implications of the inserted dark periods.
}

\author{
Stefanos Giannakis ${ }^{1,2,3}$, Ana Isabel Merino Gamo ${ }^{3}$, Efthymios Darakas ${ }^{1}$, Antoni \\ Escalas-Cañellas $^{2,4}$, César Pulgarin ${ }^{3, *}$ \\ ${ }^{1}$ Laboratory of Environmental Engineering and Planning, Department of Civil Engineering, Aristotle University of \\ Thessaloniki, 54624 Thessaloniki, Greece \\ ${ }^{2}$ Laboratory of Control of Environmental Contamination, Institute of Textile Research and Industrial Cooperation \\ of Terrassa (INTEXTER), Universitat Politècnica de Catalunya, Colom 15, 08222 Terrassa, Catalonia, Spain \\ ${ }^{3}$ Swiss Federal Institute of Technology, Lausanne, Institute of Chemical Sciences and Engineering, 1015 \\ Lausanne, Switzerland \\ ${ }^{4}$ Department of Chemical Engineering \& Terrassa School of Engineering, Universitat Politècnica de Catalunya, \\ Colom 1, 08222, Terrassa, Catalonia, Spain
}

*Corresponding author: César Pulgarin, Tel: +41216934720; Fax: +41216936161; E-mail: cesar.pulgarin@epfl.ch

\begin{abstract}
In this study, the effect of light intermittence on solar disinfection of secondary treated wastewater was investigated. Synthetic secondary effluent was spiked with $E$. coli and submitted to 3 different light intermittence regimes by circulating the effluent between a dark storage tank and three in-series illuminated reactors. The relative influence of the recirculation rate on bacterial inactivation was studied, in short (3-7 min) light regimes and a dark-to-light ratio of 2.04. Lower recirculation rates resulted in poorer disinfection results, showing the detrimental effect of longer dark storage periods on the removal efficiency. Also, longer time intervals were employed in batch tests, to investigate the effect of 1, 2 and 3-hour dark intervals, during recreated solar disinfection conditions; fourteen different scenarios were tested. Three hours of continuous or cumulative illumination were proven enough to provide the necessary dose to damage bacteria irreparably, while interruption during these hours favored bacterial resistance. Finally, absence of regrowth was observed in all cases that derived from samples with null bacterial counts. However, when a fraction of viable bacteria was present at the end of the solar treatment, survival was favored.
\end{abstract}

Keywords: Solar disinfection, synthetic wastewater, light intervals, intermittent illumination, E. coli 


\section{INTRODUCTION}

Sunlight is able to inactivate micro-organisms due to the synergistic effect of the UV and heating of water. The first ones to study the germicidal activity of sunlight were Downes and Blunt (1877), followed by others (Gameson, 1975; Mitchel, 1978; Acra et al., 1980). UV wavelengths which reach the earth's surface, along with the visible region, are classified as UV-A (320-400nm) and UV-B (290-320nm) (Rincon and Pulgarin, 2004).

Solar disinfection of water is based on the bacteriostatic effect of the UV-A solar radiation as well as on the presence of dissolved oxygen; in presence of natural photosensitizers highly reactive forms of oxygen, the reactive oxygen species (ROS), are produced, which have bactericidal effect (Gelover et al., 2006). UV-B radiation on the other hand, can cause direct DNA damage by inducing the formation of DNA photoproducts, of which the cyclobutane pyrimidine dimer (CPD), the pyrimidine (64), pyrimidinone (6-4PP) and Dewar valence isomers are the most common (Douki, 2013). The accumulation of DNA photoproducts can be lethal to cells through the blockage of DNA replication and RNA transcription (Harm, 1980; Britt, 1996, Rincon and Pulgarin, 2004).

The mechanism of inactivation, apart from the direct UV-B attacks against the bacterial DNA, is described briefly as a partial decomposition of the outer membrane, followed by disordering of the cytoplasmic membrane, resulting in cell death (Sunada et al., 2003). Vital cellular functions like the transcription and translation apparatus, transport systems, amino acid synthesis and degradation, respiration, ATP synthesis, glycolysis, the TCA cycle, chaperone functions and catalase are targeted by UVA irradiation (Bosshard et al., 2010).

When it comes to field-scale real-water or wastewater disinfection applications, two of the most crucial factors are the temperature of the treated water and the availability of light (Fabriccino and d'Antonio, 2011). In some cases, areas with poor water supplies are provided with a large number of sunny days per year (more than 3000 hours) (Meichtry et al., 2005), but for instance, solar-UV power is dependent on the clarity of the sky and the absence of clouds. Hence, studies have been made to assess the potential impact that this process has on disinfection (Rincon and Pulgarin, 2003) and the effects of intermittence in light supply on the solar disinfection process (Misstear et al., 2013). Even in the sunniest areas in the world, there is no guarantee that the UV supply will be continuous; therefore, there is a need to further investigate the mechanisms and possible implications of intermittence in the overall efficiency of the process.

Although some works have demonstrated indifference of the effect of light intermittence on some matrices (Lanao et al. 2012), this is not the rule for all microorganisms and all light waves (Velez-Colmenares et al., 2011). However, there is a general consensus that the intermittent process deviates from the behavior expected in a normal test; hence, this could be attributed to the disinfection installations as well. A very common method of solar disinfection is the compound 
parabolic collector (CPC) reactors (Malato et al., 2004), which recirculate the sample around an illuminated surface and a dark storage tank. Therefore, technical aspects can affect the process, causing intermittence, such as the storage of water in the dark tank (Moncayo-Lasso, 2009; Fernandez et al., 2005; 2009, Rincon and Pulgarin, 2007). Sciacca et al. (2011) with a minimum dark storage volume (83\% illuminated volume), reported different results while performing solar CPC intermittent tests, compared to the equivalent batch tests, stating that there are actions that intervene (such as shear forces or oxygenation of the sample) and modify the final outcome. Finally, Ubomba-Jaswa et al. (2009), concluded that the continuous manner of irradiation has greater inactivation potential, compared to the interrupted manner of solar UV light supply.

The revision of the said situations reveals that there is a significant gap in scientific literature on photolytic processes for wastewater treatment -particularly on the effect of light intermittence- compared to the amount of work devoted to drinking water treatment. The present work contributes directly to the limited resources of this knowledge area, in order to assess the potential applications of solar treatment in water reclamation in sunny areas or areas with poor water quality, which can greatly influence the amounts of water supply (Gamage and Zhang, 2010).

In this study, the solar disinfection of secondary treated wastewater under intermittent illumination was simulated in a lab-scale plant, using a synthetic secondary effluent and controlled laboratory conditions, namely, predefined light supply, wastewater composition, and microorganisms (E. coli). The microbial response to different light and dark phases was evaluated. Specifically, this study focuses on:

1. High-frequency intermittence (3-6 cycles per hour) by recirculating wastewater between a dark storage tank and an illuminated area. The recirculation in this setup imitates a compound parabolic collector reactor (CPC), a typical solardisinfection configuration.

2. Low-frequency intermittence, by inserting 1-h, 2-h or 3-h dark phases into 6hour batch disinfection tests. These tests simulate the breaks in high-intensity light caused by temporal clouding in solar batch-reactor applications.

3. The results were evaluated through process efficiency, in terms of viable plate counts throughout the tests. Also, dark repair (DR) of the bacterial population was studied on the disinfected samples.

\section{MATERIALS AND METHODS}

\subsection{Synthetic secondary effluent preparation}




\subsubsection{Microbial methods}

The E. coli strain K12 (MG1655) used for the experiments was supplied by the "Deutsche Sammlung von Mikroorganismen und Zellkulturen". Luria-Bertani

(LB) broth (10 g Bacto $^{\mathrm{TM}}$ Tryptone, $5 \mathrm{~g}$ Yeast extract, $10 \mathrm{~g} \mathrm{NaCl}$, per liter) was prepared for each experimental series by suspension in Milli-Q water and heatsterilization by autoclaving. One colony was picked from the pre-cultures and loopinoculated into a $50 \mathrm{~mL}$ sterile falcon, containing $5 \mathrm{~mL}$ of LB broth. The flask was then incubated at $37^{\circ} \mathrm{C}$ and $180 \mathrm{rpm}$ in a shaker incubator. Further dilution was made after $8 \mathrm{~h}$ in 1\% v/v and the new solution was incubated under the same conditions for 15 more hours.

Cells were harvested during the stationary phase by centrifugation from batch culture for 15 minutes at $5000 \mathrm{rpm}$ and at $4^{\circ} \mathrm{C}$, in a universal centrifuge. After centrifugation the bacterial pellet was re-suspended and washed for 5 minutes under the same centrifugation conditions. Rinsing was repeated twice and the final pellet was re-suspended into the initial volume. Washing and re-suspension was done in heat-sterilized pure saline solution $(\mathrm{NaCl} 8 \mathrm{~g} / \mathrm{L}$ and $\mathrm{KCl} 0.8 \mathrm{~g} / \mathrm{L}$, neutral $\mathrm{pH}$, regulated with $\mathrm{NaOH}$ ). The above described procedure resulted in a bacterial pellet of approximately $10^{9}$ colony forming units per milliliter (CFU/mL).

\subsubsection{Wastewater Composition}

The composition of the synthetic wastewater which in all experiments was a 1/10 dilution of the composition used by Velez-Colmenares et al. (2011) shown in Table 1. The preparation of the artificial wastewater included dilution of $1 \mathrm{~mL}$ of the concentrated bacterial solution of synthetic sewage, which results to an initial population of $10^{6} \mathrm{CFU} / \mathrm{mL}$.

\subsection{Light source}

Solar irradiation was simulated by a Hanau Suntest (AM1) lamp. This Xenon lamp has a light spectral distribution of about $0.5 \%$ of the emitted photons at wavelengths shorter than $300 \mathrm{~nm}$ (UV-C range) and about 7\% between 300 and 400 $\mathrm{nm}$ (UV-B to UV-A range). The Suntest system contained a basic uncoated quartz glass light tube and an IR screen, plus a cut-off filter for wavelengths under $290 \mathrm{~nm}$. The spectrum over $300 \mathrm{~nm}$ follows the natural solar one, while the intensity was set at $1200 \mathrm{~W} / \mathrm{m}^{2}$.

\subsection{Description of reactors}




\subsubsection{Recirculation reactors for high-frequency intermittence experiments}

In the set-up presented in Figure 1, synthetic wastewater from a dark storage vessel $(400 \mathrm{~mL})$ was pumped by a peristaltic pump through three glass reactors (diameter $3.8 \mathrm{~cm}$, effective irradiation surface $214.8 \mathrm{~cm}^{2}$ ), connected in series, of total volume $230 \mathrm{~mL}$. The third reactor effluent was fully recirculated back to the dark storage vessel. The in-series reactors were irradiated by the Suntest apparatus, as explained before. Three different flowrates were essayed: 1.87, 3.44 and $4.39 \mathrm{~L} / \mathrm{h}$. The total of $700 \mathrm{~mL}$ wastewater in recirculation was completed by the water present in the recirculation system $(70 \mathrm{~mL})$. The hydraulic calculations deriving from these settings are summarized and presented in Table 2, named cases I, II and III.

Furthermore, the illuminated volume was the $32.9 \%$ of the total volume, $10 \%$ was within the recirculation system and $57.1 \%$ remained in the dark, in every moment. In terms of light, the last two percentages constitute the total volume in the dark and the subsequent dark-to-light ratio is 2.04. This rate was constant within the three cases. Hence, the problem is reduced to the effect of the number of full cycles achieved within the 4 hours of the experiment and whether it affects the disinfection rate.

\subsubsection{Low-frequency intermittence in batch tests}

The second part of the experiments, that included light intervals of 1-3 hours, was also developed in a Suntest apparatus and included the irradiation of the wastewater sample and its stoppage by removing the reactors from the light source. 50 $\mathrm{ml}$ batch reactors were used, made from Pyrex Glass (diameter $3.8 \mathrm{~cm}$, height $9 \mathrm{~cm}$ with cap neck included, total volume $60 \mathrm{~mL}$, effective irradiation surface $70.6 \mathrm{~cm}^{2}$ ), over constant mild stirring.

Within six hours, there can be 14 different combinations of light intermission, for 1, 2 and 3-hour light stoppage. Sampling was performed hourly, regardless whether the sample was illuminated or not; reactors were removed from the Suntest and placed inside a dark box in ambient temperature. Initial bacterial population was approximately $10^{6} \mathrm{CFU} / \mathrm{mL}$ in all experiments. Table 3 presents a summary of the 14 different scenarios, indicating the interval of time without light exposure. Scenarios 14 withhold $1 \mathrm{~h}$ of break, scenarios 5-10 of $2 \mathrm{~h}$ and scenarios 11-14 of 3 hours.

\subsection{Post-irradiation measurements}

Dark repair of the $E$. coli present in the artificial wastewater was studied in ambient temperature $\left(20-25^{\circ} \mathrm{C}\right)$, in absence of light, following the irradiation of the sample. The wastewater samples acquired during hourly sampling of the disinfection study of both high and low-frequency experiments, were stored in $1.5 \mathrm{~mL}$ sterile Eppendorf caps or the very same batch reactor previously exposed under illumination. 
The survival of $E$. coli was measured $24 \mathrm{~h}$ after every sampling time while regrowth was measured after 24 and $48 \mathrm{~h}$ in the dark for the final sample, after 4 hours of illumination.

\title{
2.5. Determination of bacterial counts
}

Bacterial population was monitored by pour-plating on PCA. At each data point, $1 \mathrm{~mL}$ of sample was withdrawn from either the recirculation tank or the batch reactor, according to the experimental set-up. Aliquots were done to achieve 20-100 colonies/plate and plating was done in duplicates; hence, presented here are the mean values.

\section{RESULTS AND DISCUSSION}

\author{
3.1. High-frequency intermittence experiments (simulation of a CPC \\ recirculation)
}

\subsubsection{Disinfection of the bacterial population under different cases of recirculation} flow rates

Figure 2 shows the evolution of disinfection throughout the 4-hour light intermittence experiments. A slight increase in bacterial concentration is observed in the non-irradiated control, which is consistent with nutrient presence in the synthetic secondary effluent, and with dark conditions. The continuous irradiation control shows a consistent exponential reduction in E. coli of $6 \log _{10}$ units in 3 hours $\left(2 \log _{10}\right.$ per hour). Introduction of light intermittence (2.04 dark-to-light ratio) drastically impaired disinfection, yielding poorer bacterial inactivation in $3 \mathrm{~h}: 0.62,0.33$, and $0.06 \log _{10}$, for cases I, II and III. Slightly better values, were obtained at the end of the experiment (4h), numbering $0.87,0.49$ and $0.14 \log _{10}$ units for cases I, II, and III, respectively (see Table 2).

All light intermittence experiments applied a total irradiation time of $78.9 \mathrm{~min}$. However, experimental kinetics proved to be very sensitive to the recirculation rate, i.e., to the length of the irradiation/dark cycle. As shown in Figure 2, disregarding transient effects during the early latency period, inactivation rates were greater for greater recirculation rates. This is in accordance with a previous research by Fernandez et al. (2005). These authors speculated that their bacterial inactivation is due to mechanical stress; however, our maximum recirculation rate was almost 70 times lower than their minimum and the subsequent stress considerably lower as well. 
Dark control experiment was performed in the same experimental setup and growth of the population was observed instead. Consequently, inactivation due to mechanical stress under our experimental conditions is either negligible or lower than the bacterial growth rate.

The disinfection curves in Figure 2 also reveal that the most important observation lies within the correlation between the flow rate and the overall inactivation efficiency. It is shown that as the recirculation rate rises, and therefore the completed recirculation around the illuminated part, higher bacterial inactivation is achieved as the cumulative dose increases and, in absolute numbers, rates of 87.1, 49.3 and $14.3 \%$ were obtained in cases I, II and III, respectively. In absence of intermittence, the profound effect of intermittence is demonstrated by the total inactivation achieved in 3 hours of non-intermittent illumination.

It is also shown that the sample that recirculates faster spends more intervals in the sun, although shorter ones. That leads to more frequent exposure to sunlight and according to multi-hit and multi-target theory of Harm (1980), more effective illumination periods, as proved by Berney et al. (2006). This takes place because the light source is given more opportunities to hit the $\mathrm{n}$ number of sites needed to inactivate the bacteria. However, when the recirculation rate is lower, the longer dark storage times are strongly affecting the process, giving the necessary time to bacteria to recover from the hits taken during the exposure time. Even in slightly turbid waters, bacteria can be sheltered by aggregation and shading from particles against light attacks. Therefore, faster recirculation disaggregates the bacteria in the suspension and with the aid of the higher appearance rate under the light source, bacterial disinfection is favored.

All curves in Figure 2 reveal a fluctuation in inactivated bacteria within the first two hours. Lower recirculation rates during the first hour lead to larger initial bacterial inactivation, due to the longer light exposure; the experimentation is initiated with the three reactors into the solar simulator filled with suspended bacteria that suffered longer initial non-interrupted light exposure. Also, subsequent longer dark storage times resulted in sharper transient adaptation or recovery with local maxima. In other words, during the first 60 minutes, the lower recirculation rates, that spend longer un-interrupted periods in the light, presented lower bacterial numbers, contrary to the higher recirculation rates, that demonstrated a relatively constant population. On the one hand, bacterial growth is favored in this rich in nutrients medium, and result to bacterial growth in the dark tank. On the other hand, the recirculation did not allow to spend long time in the dark, but slowly accumulate the necessary dose required, while limiting the growth in the dark. Also, notice should be taken on the positions of the sampling and recirculation tubes; the positions were chosen to avoid short-circuiting and therefore false bacterial numbers.

Moreover, it is shown that there is a variable period of adjustment of the bacterial population to the new conditions; 100 minutes for the highest recirculation rate and around 180 minutes for the lowest one. This is a common observation in almost all sun-driven experiments and is often expressed as a shoulder effect (Harm, 1980; Sinton et al., 1999; Berney et al., Ndounla et al., 2013); in continuously 
irradiated samples, this phenomenon is attributed to initial defense mechanisms, but here it reveals the need for a cumulative amount of dose that is required to be provided in order to efficiently decrease the populations, as described by Misstear et al (2013).

In addition, the factor of temperature was neglected and not accounted as a possible inactivation path for bacteria. Water temperature was measured along the experiment with a thermometer in the storage tank and the measured values ranged between room temperature $\left(21^{\circ} \mathrm{C}\right)$ and $32^{\circ} \mathrm{C}$, stabilized around the upper edge. It has been reported that $E$. coli after being dispersed in water solutions are stable between these temperatures, because there is no thermal effect on bacterial viability (Fernandez et al., 2005; Sichel et al., 2007)

According to Sichel et al. (2007), around this temperature the metabolic activity of bacteria is higher, leading to higher risks of osmotic damage to the cells. However, the aquatic matrix that withheld the bacterial suspension is artificially recreated wastewater, simulating the effluent of secondary treated wastewater. Thus, anions and organic matter from the wastewater provide nutrients for bacteria; their viability is maintained in higher levels than the experiments held in distilled or demineralized water matrices and the osmotic pressure is of minimum effect. The solution of wastewater already contains calcium and magnesium ions, which are the first ions detected in suspension when bacterial cells are subject to lysis in unfriendly environments (Marugan et al., 2010). Therefore, cell’s demands for survival are met.

\subsubsection{Bacterial regrowth due to dark repair mechanisms after high-frequency intermittence irradiation}

Figure 2 shows the bacterial regrowth after 24 and 48 hours by the end of the experiment. No regrowth was observed after 48 h, while only one of the samples (corresponding to the maximum recirculation rate) presented some regrowth after 24 h. Figure 3 presents the regrowth and the bacterial survival rate as well. In most cases it is shown that the applied light dose in this particular intensity was enough to permanently damage the bacteria after one hour of cumulative exposure. As the process continues, the germicidal effect of light is more obvious, but not definite (see Figure 2, $4.39 \mathrm{~L} / \mathrm{h}$, bar: $180 \mathrm{~min}$ ). A longer observation period could reveal for both cases whether survival is permanent or temporal.

It can be also observed that in overall, the applied irradiation time, of 78.16 minutes, is enough to reduce bacterial regrowth potential for at least $48 \mathrm{~h}$ of subsequent dark storage. Moreover, Figure 2 clearly shows a trend of lower survival rates after 24 and $48 \mathrm{~h}$ of dark storage, for samples previously submitted to rising recirculation rates. It is clear that as recirculation rate increases, the regrowth potential of bacteria is increased as well. As percentage of initial bacterial concentration, the survival rate is $14.1,11.3$ and $8.80 \%$, for cases I to III, respectively. 
As described before, longer dark periods result in more time available for bacteria to repair and deploy defense mechanisms, even if bacteria have previously suffered longer illumination periods. Similar observations were made by Rincon and Pulgarin (2003), noting the importance of intermittence in survival of bacteria. Hence, intermittence has an effect in regrowth as well; the same defense mechanisms described by Misstear et al (2013) strengthen bacteria and favor their survival. It must be reminded that bacterial growth is favored in this matrix, due to the presence of nutrients, and the long-term effect of bacterial inactivation is due to their inability to survive, and not from external or environmental factors. Therefore, the integrated light dose applied during the intermittent irradiation has been enough to induce an irreversible damage, in an extent enough to limit bacterial regrowth for the following $48 \mathrm{~h}$. The importance of estimating this period was highlighted by Rincon and Pulgarin (2003) and as it seems in our case UV has rendered bacteria unable to reproduce and probably has inflicted lethal damage after the 4 hours of experiment, which ensures bacterial decay in the post-irradiation period. The neighboring bacterial counts after 1 and 2 days indicate that under our conditions the dose is the decisive parameter, when regrowth is under question, since similar cumulative light dose resulted to similar bacterial counts.

\subsection{Low-frequency intermittence in batch tests (cloud simulation)}

\subsubsection{1-hour dark intervals}

Figure 4a presents Scenarios 1 to 4 (see Table 3), in terms of bacterial population over time. In these scenarios, 1-hour illumination stoppage was performed, during the $2^{\text {nd }}, 3^{\text {rd }}, 4^{\text {th }}$ or the $5^{\text {th }}$ hour of the experiment. There is a series of findings within this graph, which demonstrate the importance of continuous illumination of the bacterial sample. For instance, Scenario 4 receives un-interrupted illumination until the 5th hour and as a result, total inactivation takes place in 3 hours. Same applies for Scenarios 2 and 3, where 2 and 3 hours of continuous irradiation is provided to the samples.

By applying an irradiance of $1200 \mathrm{~W} / \mathrm{m}^{2}$ it is shown that this time period of 23 hours is enough to inflict lethal or, at least, non-repairable damage; after 3 hours, illumination was paused for an hour and bacteria, initially enumerated close to the detection limit, were no longer viable. Common characteristic in all the runs, a shoulder effect during the first hour of illumination, as discussed above and by previous researchers (Berney et al., 2006; Misstear et al., 2013). Effort was made to maintain the bacteria in stationary phase before their introduction to the synthetic wastewater so as to eliminate this concern. However, the first phases of adaptation in the new environment are usually unstable and here, along with the presence of nutrients, the favored bacterial growth is hindered by the strong and continuous illumination. Therefore, the shoulder effect is visible in all scenarios. 
Finally, it is clear that bacterial inactivation is favored when the dark interval takes place in the last hours. In the case that inactivation was complete during illumination, it is shown that there is no obvious recovery of the bacterial population within the studied 6 hours. The introduction of an early dark period of $1 \mathrm{~h}$ resulted in an increase in the required time for total disinfection. The earlier the 1-h dark interval was introduced, the longer the increase in the time required for total disinfection: 2 additional hours when darkness was applied during the second hour, 1 additional hour if in the third hour, 1 additional hour when applied in the third hour. The required time for total disinfection significantly decreases with increasing lengths of the initial uninterrupted irradiation time: From $300 \mathrm{~min}$ for $1 \mathrm{~h}$ to $180 \mathrm{~min}$ for $4 \mathrm{~h}$ of uninterrupted irradiation time.

\subsubsection{2-hour dark intervals}

In figure $4 \mathrm{~b}$ are presented the Scenarios 5 to 10 , demonstrating the disinfection curves of the experiments including a 2-hour break within the irradiation. The normalized disinfection data presented in this Figure, suggest clearly a modification on the kinetics of the inactivation process. In the case of 1-hour intervals the disinfection curves were almost linear after the initial shoulder; in this Figure the linearity is kept in the cases with three consecutive hours of illumination, before or after the dark period, especially when the 2-hour dark period is consequent. Clearly different slopes are generally observed in the segments corresponding to dark periods (dotted lines), reflecting the absence of disinfecting force.

The subsequent inactivation after the temporal stoppage of the irradiation is interesting, due to the inability of bacteria to reproduce and in parallel, the infliction of damage heavy enough to make it impossible to recover. It has been reported that UV-irradiated E. coli present accelerated senescence, an irreversible state of dormancy, due to the accumulated damage in cell's components over time (Stephens, 2005; Bosshard et al., 2010). Therefore, remaining bacteria fall into either the alive and active category that continue to reproduce or the dormant ones. In terms of total disinfection times, they vary from 3 to 5 hours, similarly to the 1-hour Scenarios; however, it is observed that two or three hours of non-stop irradiation is of irreversible effect. Similarly as the 1-hour intervals, the total experimental time decreases from Scenario 5 to 10.

Scenario 10 describes the only case of constant illumination during the first 3 hours and therefore demonstrates the smallest required time for total disinfection. Conversely, Scenarios 5, 6 and 8, describe the worst case; the sample of Scenario 5, after 1 hour of illumination is kept two hours in the dark, allowing the pre-mentioned repair and defense mechanisms to be developed. Hence, the overall required time is greater. Scenario 6 is also one of the worst possible scenarios, because of the same protection methods described before; every one hour irradiation is stopped for one hour and the fluctuations in intensity increase the chances of bacteria to escape the lethal effect of solar light. Also, during Scenario 8, the necessary 3 hours of 
irradiation are interrupted by two hours of dark storage. Similarly to Scenario 5, this effect leads to a total of 5 hours for total inactivation. Finally, Scenarios 7 and 9 represent a 2-hour non-continuous interval, where one of the 2-hours break took place after disinfection was complete.

\subsubsection{3-hour dark intervals}

The last tests concern 3-hour continuous or intermittent breaks; 4 scenarios, Scenario 11 to Scenario 14 are presented in Figure 4c. The time needed for total inactivation are similar among scenarios, approximately 6h. The kinetics of each scenario are reflected in the steepness of the curves, with the less inclined parts highlighting the dark storage periods. Scenario 14 demonstrates the fastest inactivation rate, being the only that receives light for 2 hours in a row, followed by Scenario 13, 12 and 11. Scenario 13 is more effective than Scenario 12, because of the extra hour illumination it receives, compared to the ones of Scenario 12. Scenario 11 is the worst case scenario, because it represents a situation where 60 minutes of illumination are followed by 180 minutes of dark storage. All the actions that prevent bacterial decay are present here; however, this light intensity is enough to inflict considerable damage on bacteria.

These findings verify once more that in a period of six hours, the bacterial population is eliminated. It is concluded from these scenarios that in our conditions there is a cumulative amount of light dose to be gathered before total disinfection; a dose corresponding to the total amount of 3 hours in this irradiance is enough to disinfect bacteria in artificial wastewater. For lower light intensities, lower rates and, therefore, higher required times are expected, in accordance with the findings of other researches (Benabbou et al., 2007). However, the investigation shows a significant degree of tolerance to illumination interruption for some hours. These results are encouraging, under the scope of extrapolation to the real light situations.

\subsubsection{Durability of the process - Bacterial regrowth due to dark repair mechanisms}

In order to assess the regrowth risk of the disinfected samples, the glass batch reactors were kept in the dark for 48 hours and sampling was made every 24 hours of storage in the dark, in ambient temperature, as described in the previous section. The scenarios selected and presented in Figure 4d are Scenario 2, 8 and 14. They were selected as an average case, of 2-hour constant exposure to sun rays and then submitted to 1, 2 or 3 hours of constant dark storage. Also presented, is a disinfection experiment in the exact same conditions, but without light intervals.

The importance of dark storage has been stated before; therefore, 1, 2 and 3 hours of dark storage would be expected to present increasing survival rate, accordingly to the effect of repair during the experiment. As it seems, these mechanisms were completely unable to reactivate bacteria while stored in the dark. 
The cumulative amount of solar irradiation has probably exceeded the threshold needed to completely inactivate life functions of bacteria. All scenarios presented no regrowth, regardless of the presence or absence of dark intervals.

Comparing these results with the effects of light intermittence in the previous experimental set-up, it seems that the most decisive parameter concerning bacterial inactivation, as well as dark repair, is the continuous, un-interrupted exposure to light. Although in both cases the irradiation rendered bacteria unable to regrow, it was due to the continuous illumination type and the bigger light residence times that the process became more efficient. In the latter case of the fourteen scenarios, since total inactivation is reached, no bacterial regrowth is observed, indicating their destruction since no reappearance is observed in any case, when in a favorable environment.

\section{CONCLUSIONS}

The results of this study revealed that for short intermittent parts within a short period of exposure to light, recirculation speed in mechanically non-damaging rates was directly influencing bacterial inactivation. Higher speeds resulted in a less fluctuated disinfection process, due to the higher frequency of illumination, when compared to longer periods with the same total time of exposure. Slower recirculation rates enhanced bacterial defense mechanisms and promote growth, resulting in lower inactivation rates.

Also, in the intensity employed, a period of 2-3 hours of exposure to light has been proven an adequate time to effectively disinfect wastewater, by inflicting irreparable damage. Long dark intervals, when posed early in the disinfection process hindered bacterial inactivation. Concerning the kinetics of the process, the kinetics of each light interval scenario performed reflect light and dark periods by the change in curve slopes. Plus, the results of different illumination conditions during the first hour of light exposure confirmed the crucial importance of continuous, constant irradiation during this period. When these conditions prevailed, a 1-h shoulder occurred. Upon the infliction of intermittence in light supply, a shoulder up to 3-h was observed.

Moreover, it is promising that within a period of 6 hours, regardless of the existence of light intermission or not, total disinfection was achieved; the cumulative light dose necessary to disinfect wastewater was achieved within 3 hours of accumulated illumination. However, for lower light intensities higher exposure times will be expected, if the light supply is not continuous.

As far as the post-irradiation events are concerned, bacterial regrowth due to the dark repair mechanisms was not observed when total inactivation was achieved. In most cases the total exposure time and the corresponding dose was enough to render the bacteria population unable to regrow. Intermittence directly influences inactivation rate during illuminated periods but apart from the trials that achieved total inactivation, the high frequency intermittence demonstrated similar active bacterial 
counts, regardless of the recirculation rates. In low frequency intermittence experiments, the post-irradiation events are similar, attributed to the lethal dose achieved within the disinfection period. When total inactivation is not achieved, partial survival of bacteria in the wastewater is also observed, due to the existence of nutrients in the water matrix. If an energy threshold exists, after which the dark repair mechanism is no longer able to help bacteria recover, it seems that it has been achieved. This point has to be further examined by proper set-up, but for sure, the tests prove that effective suppression of growth has been achieved, even in a friendly environment for bacterial populations.

Such results leave an open window of opportunity of applying solar-driven disinfection of wastewater in greater extents, even in areas with interruptions during the planned experimental times. What is more important, however, is the highlighting of design strategies if the use of a CPC is intended; the tested dark-to-light ratio is one of the numerous possibilities when designing the system. The study of both high and low-frequency intermittence allows to take into account these results in other more feasible solutions in the less favored areas, such as ponds; the influence of dark periods mitigates the effects of solar disinfection and this work can contribute to the estimation of their design parameters. Even in relatively unfavorable hydraulic conditions for disinfection, the solar disinfection methods applied render the disinfected water able to be considered for secondary uses, thus saving from the drinking water supplies of the arid areas.

\section{ACKNOWLEDGEMENTS}

The authors wish to thank, in order of acquisition, the Mediterranean Office for Youth Program (MOY, call 2011-2014), by means of which Mr. Stefanos Giannakis has received a PhD mobility grant (MOY grant $N^{\circ} 2010 / 044 / 01$ ) in the joint Environmental Engineering Doctoral Program. Also would wish to thank the Swiss Government for the Swiss Government Excellence Scholarship, by means of which Mr. Stefanos Giannakis has received a Research Visit fellowship (No. 2012.0499).

\section{REFERENCES}

1. Acra, A., Jurdi, M., Mu’allem, H., Karahagopian, Y. and Raffoul, Z., 1980. Water disinfection by solar radiation. Assessment and application. IDRC-TS66e, International Development Research Centre, Ottawa.

2. Benabbou, A. K., Derriche, Z., Felix, C., Lejeune, P., \& Guillard, C., 2007. Photocatalytic inactivation of Escherichia coli: Effect of concentration of $\mathrm{TiO}_{2}$ and 
microorganism, nature, and intensity of UV irradiation. Applied Catalysis B: Environmental, 76(3), 257-263.

3. Berney, M., Weilenmann, H. -U., Simonetti, A., Egli, T., 2006. Efficacy of solar disinfection of Escherichia coli, Shigella flexneri, Salmonella Typhimurium, and Vibrio cholera. Journal of Applied Microbiology, 101, 828-836.

4. Bosshard, F., Riedel, K., Schneider, T., Geiser, C., Bucheli, M., Egli, T., 2010. Protein oxidation and aggregation in UVA-irradiated Escherichia coli cells as signs of accelerated cellular senescence. Environmental microbiology, 12(11), 2931-2945.

5. Britt, A.B., 1996. DNA damage and repair in plants. Annual Review of Plant Physiology and Plant Molecular Biology, 47, 75-100.

6. Douki, T., 2013. The variety of UV-induced pyrimidine dimeric photoproducts in DNA as shown by chromatographic quantification methods. Photochemical \& Photobiological Sciences, 12, 1286-1302.

7. Downes, A. Blunt, T.P., 1877. Researches on the effect of light upon bacteria and other organisms. Proceedings of the Royal Society of London, 26, 488-500.

8. Fabriccino, M., d' Antonio, L., 2011. Use of solar radiation for continuous water disinfection in isolated areas. Environmental Technology, 33 (5), 539-544.

9. Fernández, P., Blanco, J., Sichel, C., and Malato, S., 2005. Water disinfection by solar photocatalysis using compound parabolic collectors. Catalysis Today, 101, 345-352.

10. Fernández-Ibáñez, P., Sichel, C., Polo-López, M. I., de Cara-García, M., \& Tello, J. C., 2009. Photocatalytic disinfection of natural well water contaminated by Fusarium solani using $\mathrm{TiO}_{2}$ slurry in solar CPC photo-reactors. Catalysis Today, 144(1), 62-68.

11. Gamage, J., Zhang, Z., 2010. Applications of Photocatalytic Disinfection. International Journal of Photoenergy, Vol. 2010, Article ID 764870, 11 pages.

12. Gameson, A. H. L., 1975. Discharge of Sewage from Sea Outfalls, Pergammon Press, Oxford.

13. Gelover, S., Gómez, L., Reyes, K., Leal, T.M., 2006. A practical demonstration of water disinfection using $\mathrm{TiO}_{2}$ films and sunlight. Water Research, 40 (17), 3274-3280.

14. Harm, W., 1980. Biological Effects of Ultraviolet Radiation, Chapter 8, Cambridge University Press, New York.

15. Lanao, M., Ormad, M.P., Mosteo, R., Ovelleiro, J.L., 2012. Inactivation of Enterococcus sp. by photolysis and $\mathrm{TiO}_{2}$ photocatalysis with $\mathrm{H}_{2} \mathrm{O}_{2}$ in natural water. Solar Energy, 86 (1), 619-625.

16. Malato Rodrıguez, S., Blanco Gálvez, J., Maldonado Rubio, M. I., Fernández Ibáñez, P., Alarcón Padilla, D., Collares Pereira, M., ... \& Correia de Oliveira, J., 2004. Engineering of solar photocatalytic collectors. Solar Energy, 77(5), 513-524.

17. Marugan, J., van Grieken, R., Pablos, C., Sordo, C., 2010. Analogies and differences between photocatalytic oxidation of chemicals and photocatalytic inactivation of microorganisms. Water Research, 44 (3), 789-796.

18. Meichtry, J., Lin, H., de la Fuente, L., Levy, I., Gautier, E., Blesa, M., Litter, M., 2005. Low-cost $\mathrm{TiO}_{2}$ photocatalytic technology for water potabilization in plastic 
bottles for isolated regions. Photocatalyst Fixation. Journal of Solar Energy Engineering, 129, 119-126

19. Misstear, D.B., Murtagh J.P. and Gill, L.W., 2013. The effect of dark periods on the UV photolytic and photocatalytic disinfection of Escherichia coli in a continuous flow reactor. Journal of Solar Energy Engineering, 135(2), 021012-9.

20. Mitchell, R., 1978. Water Pollution Microbiology, Wiley, New York.

21. Moncayo-Lasso, A., Sanabria, J., Pulgarin, C., \& Benitez, N., 2009. Simultaneous E. coli inactivation and NOM degradation in river water via photoFenton process at natural $\mathrm{pH}$ in solar CPC reactor. A new way for enhancing solar disinfection of natural water. Chemosphere, 77(2), 296-300.

22. Ndounla, J., Spuhler, D., Kenfack, C., Wéthé, J., Pulgarin C., 2013. Inactivation by solar photo-Fenton in pet bottles of wild enteric bacteria of natural well water: Absence of re-growth after one week of subsequent storage. Applied Catalysis B: Environmental, 129, 309-317.

23. Rincón, A. G., \& Pulgarin, C. 2007. Fe3+ and TiO2 solar-light-assisted inactivation of $\mathrm{E}$. coli at field scale: Implications in solar disinfection at low temperature of large quantities of water. Catalysis today, 122(1), 128-136.

24. Rincón, A.-G., Pulgarin, C., 2003. Photocatalytical inactivation of E. coli: effect of (continuous-intermittent) light intensity and of (suspended-fixed) $\mathrm{TiO}_{2}$ concentration. Applied Catalysis B: Environmental, 44 (3), 263-284.

25. Rincón, A.-G., Pulgarin, C., 2004. Field solar E. coli inactivation in the absence and presence of $\mathrm{TiO}_{2}$ : Is UV solar dose an appropriate parameter for standardization of water solar disinfection? Solar Energy 77, 635-648.

26. Sciacca, F., Rengifo-Herrera, J. A., Wéthé, J., \& Pulgarin, C., 2011. Solar disinfection of wild Salmonella sp. in natural water with a 18L CPC photoreactor: Detrimental effect of non-sterile storage of treated water. Solar Energy, 85(7), 13991408.

27. Sichel, C, Blanco, J., Malato, S., Fernandez, P., 2007. Effects of experimental conditions on E. coli survival during solar photocatalytic water disinfection. Journal of Photochemistry and Photobiology A: Chemistry 189, 239-246.

28. Sinton, L.W., Finlay, R.K., Lynch, P.A., 1999. Sunlight inactivation of fecal bacteriophages. Applied and Environmental Microbiology, 3605-3613.

29. Stephens, C., 2005. Senescence: Even Bacteria Get Old. Current Biology, Volume 15, Issue 8, 308-310.

30. Sunada, K., Watanabe, T., Hashimoto, K., 2003. Studies on photokilling of bacteria on $\mathrm{TiO} 2$ thin films. Journal of Photochemistry and Photobiology A: Chemistry, 156, 227-233.

31. Ubomba-Jaswa, E., Navntoft, C., Polo-López, M. I., Fernandez-Ibáñez, P., \& McGuigan, K. G., 2009. Solar disinfection of drinking water (SODIS): an investigation of the effect of UV-A dose on inactivation efficiency. Photochemical \& Photobiological Sciences, 8(5), 587-595.

32. Velez-Colmenares, J.J., Acevedo, A., Nebot, E., 2011. Effect of recirculation and initial concentration of microorganisms on the disinfection kinetics of Escherichia coli. Desalination, 280, 20-26. 



\section{List of Figures}

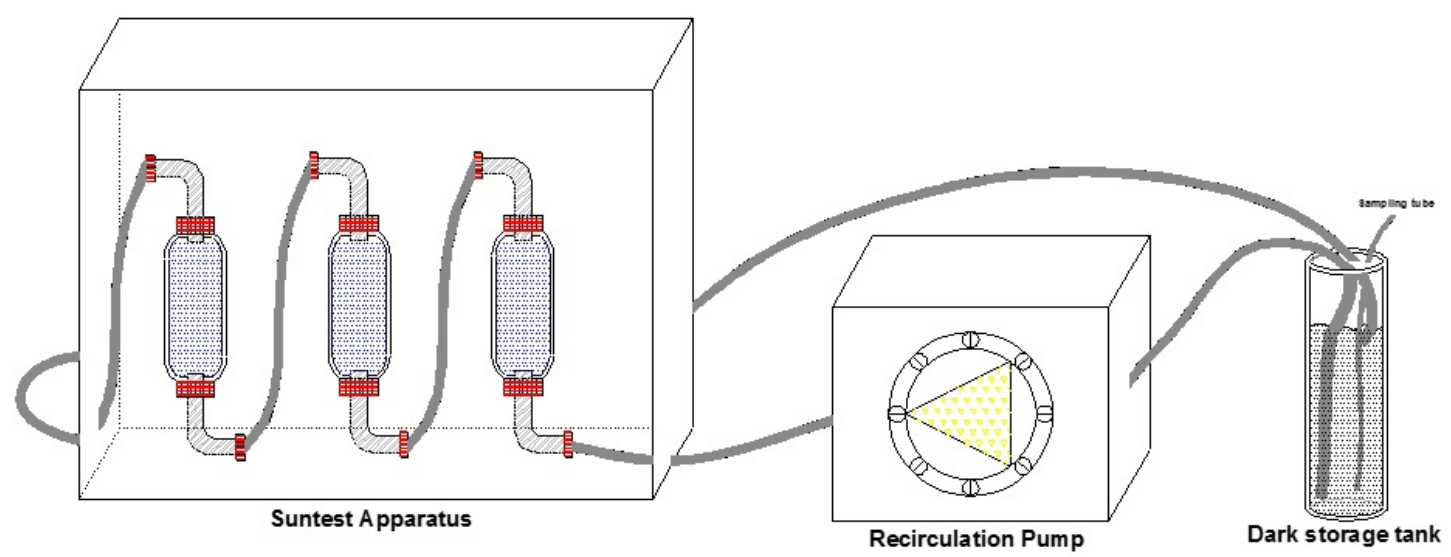

Figure 1 - The 3 in-series reactors utilized in cases I, II and III of high frequency intermittence experiments. The flow is clockwise, water is introduced at surface level and sampled at the bottom of the tank.

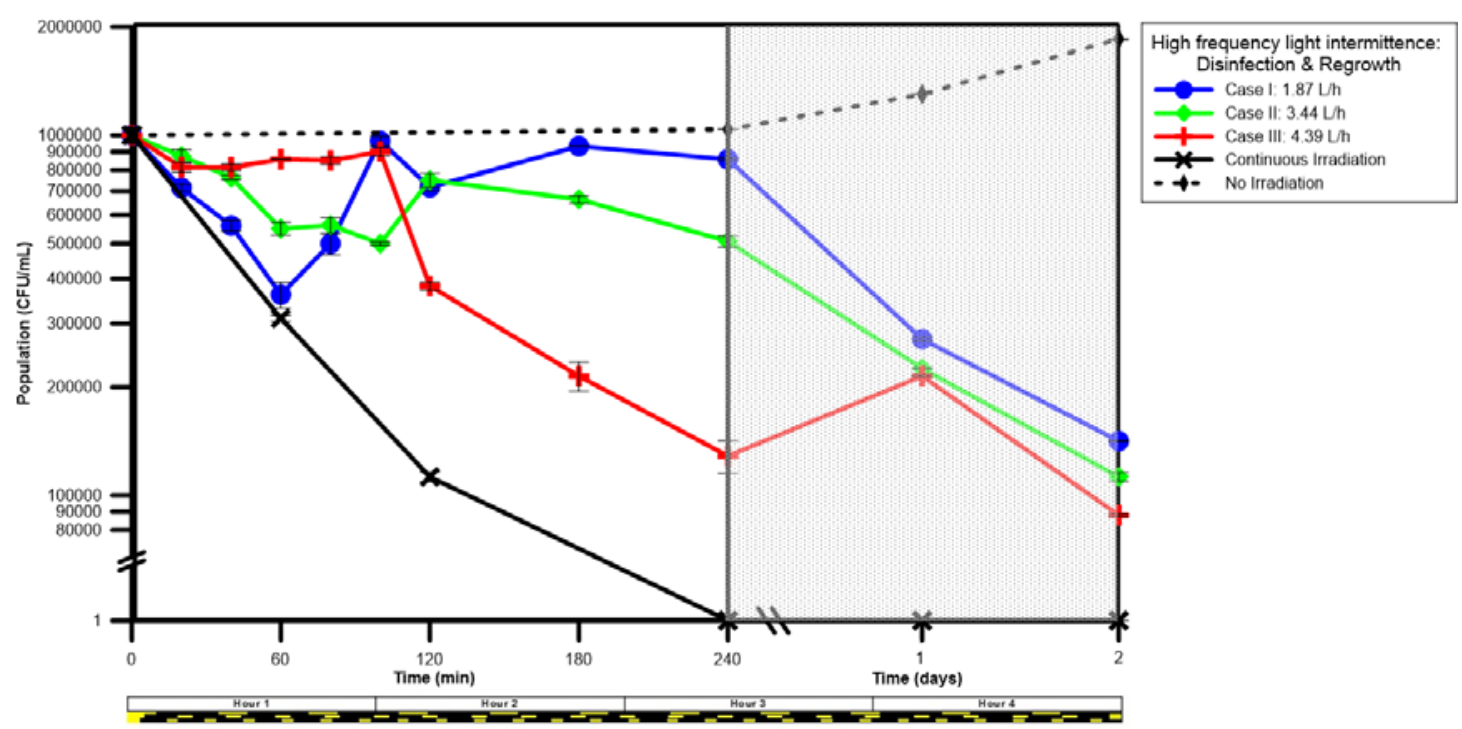

Figure 2 - Disinfection curves and subsequent regrowth of remaining bacteria after the completion of the recirculation tests, within 2 days in cases I, II and III. The accompanying graph presents the distribution of light and dark during the 4-hour long experiments. 


\section{E. coli survival after $24 \mathrm{~h}$}

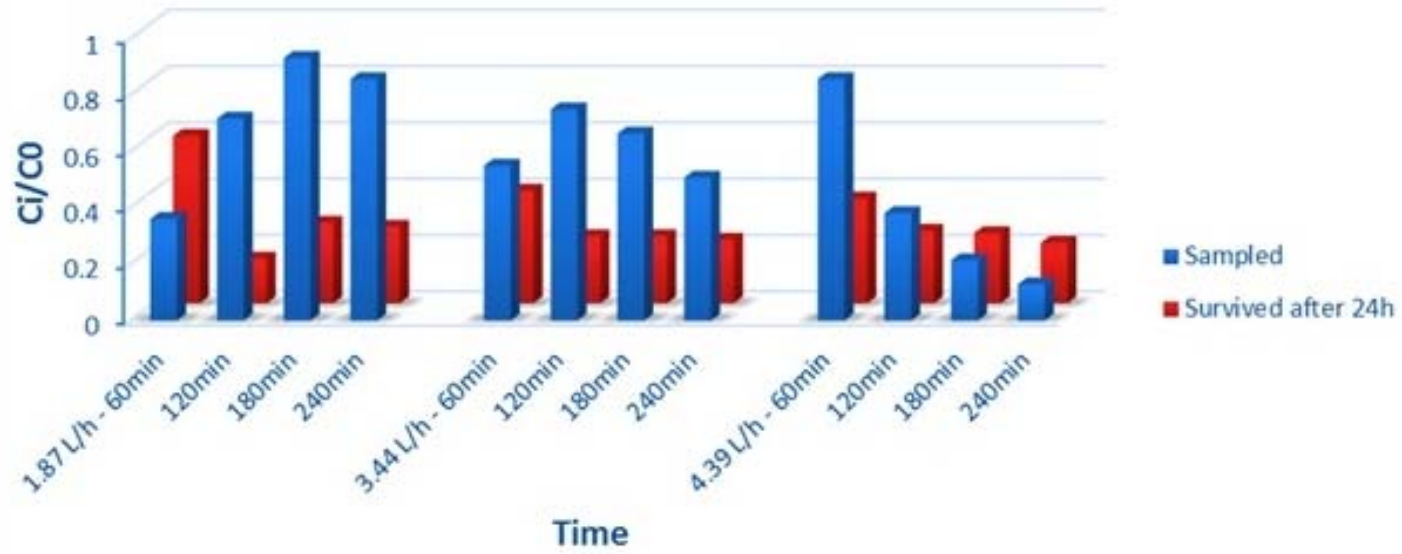

Figure 3 - E. coli survival after 24h of dark storage in cases I, II and III with recirculation rates 1.87 $\mathrm{L} / \mathrm{h}, 3.44 \mathrm{~L} / \mathrm{h}$ and $4.39 \mathrm{~L} / \mathrm{h}$, respectively. The results present the evolution of the remaining fraction of bacteria during the experiment (sampling every 1 hour), after one day (error is less than 5-10\% in all of the cases).
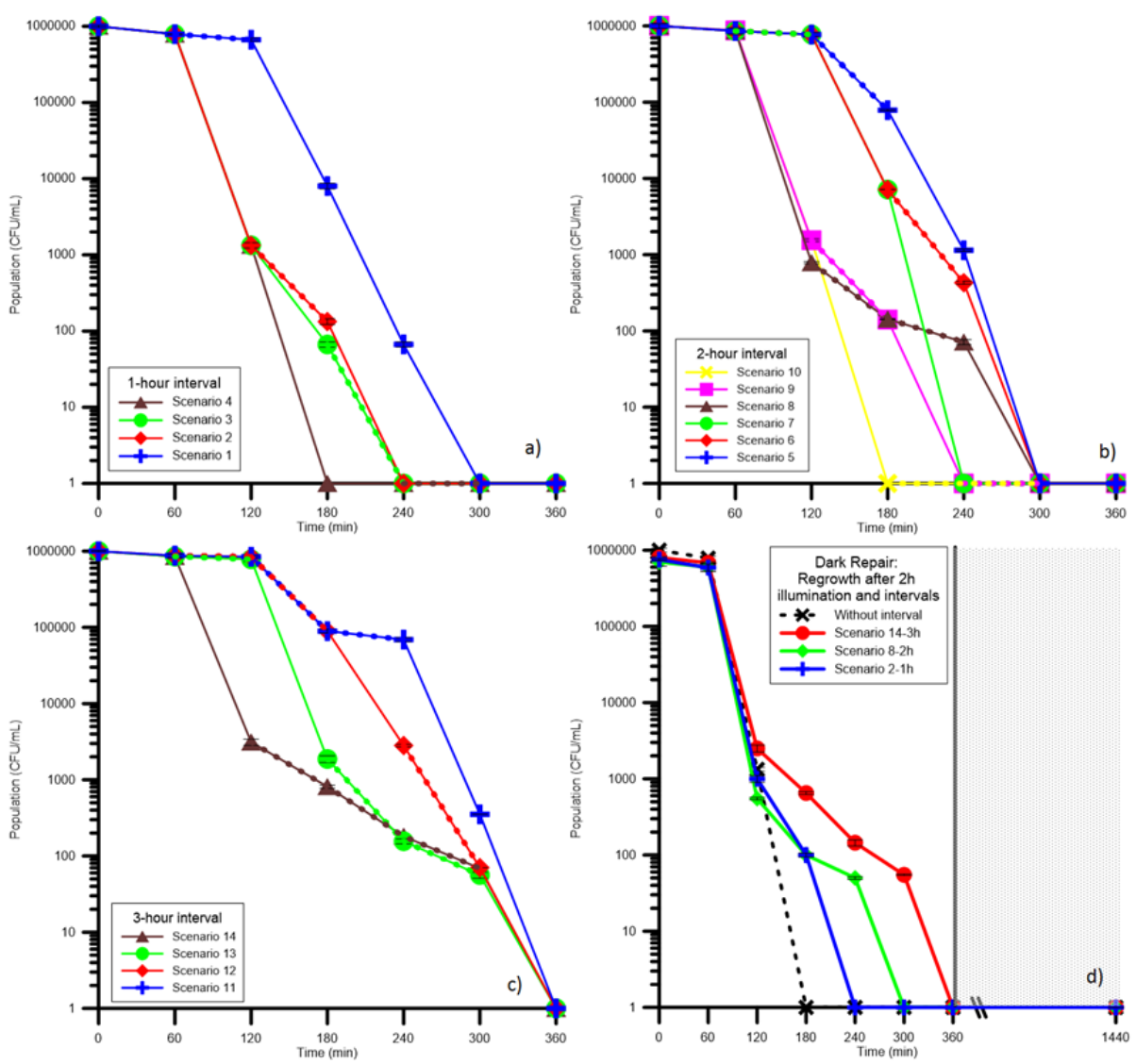

Figure 4 - 1, 2 and 3-hour light interval scenarios (a, b \& c), and regrowth of Scenarios 2, 8 and 11 (d). The continuous line represents the illuminated periods while the dotted line represents the dark intervals. 


\section{List of tables}

Table 1 - Wastewater Composition

\begin{tabular}{|c|c|}
\hline \multicolumn{2}{|c|}{$\begin{array}{c}\text { Chemical composition of the } \\
\text { synthetic municipal wastewater [24] }\end{array}$} \\
\hline Chemicals Concentration (mg/L) \\
\hline Peptone & 160 \\
\hline Meat extract & 110 \\
\hline Urea & 30 \\
\hline $\mathrm{K}_{2} \mathrm{HPO}_{4}$ & 28 \\
\hline $\mathrm{NaCl}$ & 7 \\
\hline $\mathrm{CaCl}_{2} \cdot 2 \mathrm{H}_{2} \mathrm{O}$ & 4 \\
\hline $\mathrm{MgSO}_{4} \cdot 7 \mathrm{H}_{2} \mathrm{O}$ & 2 \\
\hline
\end{tabular}

Table 2 - Summary of the hydraulic characteristics of the experiment

\begin{tabular}{|c|c|c|c|c|c|c|c|c|}
\hline \multicolumn{3}{|c|}{ Case 1: $1.87 \mathrm{~L} / \mathrm{h}$} & \multicolumn{3}{|c|}{ Case $2: 3.44 \mathrm{~L} / \mathrm{h}$} & \multicolumn{3}{|c|}{ Case 3: $4.39 \mathrm{~L} / \mathrm{h}$} \\
\hline Dark Storage Time & 15.08 & $\min$ & Dark Storage Time & 8.20 & $\min$ & Dark Storage Time & 6.42 & $\min$ \\
\hline \multicolumn{9}{|c|}{ In 240': } \\
\hline Number of Full Cycles & 11 & cycles & Number of Full Cycles & 20 & cycles & Number of Full Cycles & 25 & cycles \\
\hline Total Storage Time & 161.14 & $\min$ & Total Storage Time & 161.14 & $\min$ & Total Storage Time & 161.14 & $\min$ \\
\hline Total Time & 240 & $\min$ & Total Time & 240 & $\min$ & Total Time & 240 & $\min$ \\
\hline
\end{tabular}


Table 3 - Light Scenarios and the subsequent hourly measurements of solar disinfection efficiency.

\begin{tabular}{|c|c|c|c|c|c|c|}
\hline Scenarios & $1 h$ & $2 h$ & $3 h$ & $4 h$ & $5 h$ & $6 h$ \\
\hline S 1 & on & off & on & on & on & on \\
\hline S 2 & on & on & off & on & on & on \\
\hline S 3 & on & on & on & off & on & on \\
\hline S 4 & on & on & on & on & off & on \\
\hline$S 5$ & on & off & off & on & on & on \\
\hline$S 6$ & on & off & on & off & on & on \\
\hline$S 7$ & on & off & on & on & off & on \\
\hline S 8 & on & on & off & off & on & on \\
\hline$S 9$ & on & on & off & on & off & on \\
\hline S 10 & on & on & on & off & off & on \\
\hline S 11 & on & off & off & off & on & on \\
\hline S 12 & on & off & off & on & off & on \\
\hline S 13 & on & off & on & off & off & on \\
\hline S 14 & on & on & off & off & off & on \\
\hline
\end{tabular}

